\title{
Determination of Mitochondrial Functional State in Vital Tissues by Cytobiochemical Analysis of Peripheral Blood Lymphocytes
}

\author{
Galina A. Frelikh", Elena A. Yanovskaya, Natalia Yu. Polomeeva, Maxim S. Timofeev, \\ Vladimir A. Slepichev, Olga S. Bryushinina, Yulia G. Zyuz'kova, Roman V. Gurto, \\ Alexander S. Vasil'ev, Elena V. Semiglazova, Vladimir V. Udut \\ Laboratory of Physiology, Molecular and Clinical Pharmacology, Federal Governmental Budgetary Organization "Research Institute \\ of Pharmacology" Siberian Branch of the Russian Academy of Medical Sciences, Tomsk, Russia \\ Email: "'galina_stykon@mail.ru
}

Received February 22, 2013; revised March 20, 2013; accepted April 24, 2013

Copyright (C) 2013 Galina A. Frelikh et al. This is an open access article distributed under the Creative Commons Attribution License, which permits unrestricted use, distribution, and reproduction in any medium, provided the original work is properly cited.

\begin{abstract}
In the work, we offer a brief report by research results demonstrating correlations between energy status of peripheral blood lymphocytes and functional state of vital tissues mitochondria. Basing on our preliminary data, showing correlations between succinate dehydrogenase (SDH) activity in peripheral blood lymphocytes and speed or duration of pyridine nucleotides reduction in mitochondria of rat brain and liver tissues, we propose an idea of using cytobiochemical method of SDH estimation in peripheral blood lymphocytes for evaluation of tissue mitochondria status. The method could be successfully used in clinical practice for early revealing of energy metabolism disturbances that allows preventing disease development and optimizing the diseases therapy.
\end{abstract}

Keywords: Mitochondria; Energy Metabolism; Lymphocyte; Succinate Dehydrogenase; Cytobiochemical

\section{Introduction}

Energy exchange is essential for normal functioning of organism and it's dysfunction triggers development of pathological processes and aging $[1,2]$. The major cellular energy sources are mitochondria.

Being involved in catabolism, mitochondria utilize carbohydrates, lipids and proteins degradation products to produce high-energy substances (ATP, GTP, phosphocreatine, etc.) and water. Energy of ATP is used for various vital cellular processes. Mitochondria could participate in anabolic processes. Protein metabolism, lipid and carbohydrate exchanges are interrelated in mitochondria via Krebs cycle. Mitochondria are regulators of calcium homeostasis, cell acid-alkali balance, ROS and nitric oxide production. These organelles also participate in apoptosis and xenobiotic biotransformation [3]. Mitochondrial dysfunction leads not only to ATP depletion but metabolism disruption.

Various diseases are associated with mitochondrial dysfunction, including chronic liver diseases [4], diabetes,

\footnotetext{
"Corresponding author.
}

cancer [5], cardiovascular [6] and neurodegenerative diseases, etc. [7].

Evaluation of mitochondrial functional state in tissues provides more insight into pathogenic mechanism of various diseases, makes disorders diagnostics easier, allows diseases forecasting and gives information about drug effects on mitochondria. Early revelation of energy metabolism disturbances enables preventing pathological processes and optimizing drug therapy [7].

\section{Issues of Interest. Experimental Procedures}

Mitochondrial function is evaluated mainly in experimental research works. Existing methods of energy metabolism assessment are not realized in a clinical practice and when developing of new drugs due to these methods invasiveness, complexity and a need of using expensive special equipment $[8,9]$. Mitochondrial dysfunctions diagnostics often require a biopsy that is not always possible in clinics. It would be beneficial to have a less invasive and more accessible screening tool for monitoring tissue energy metabolism. Although several methods and 
devices have been developed for in vivo real-time assessment of energy metabolism, none of the mentioned techniques is used in daily clinical practice in any medical field [10]. The need for a practical and simple method for monitoring of the tissue energy metabolism still exists.

Pathological processes in organism start from intracellular disruptions. Cells reflect even small metabolic changes that subsequently could be detected in tissues. Peripheral blood lymphocytes could be simply isolated and supposed to be "cytochemical reflection of tissues" [11] and "indicators of the overall metabolic status of the entire organism" [12]. Nevertheless, there are no obvious proofs of the existence of correlations between lymphocyte energy status and the functional state of tissue mitochondria. The purpose of the study was to explore correlations between energy metabolism of peripheral blood lymphocytes and the functional state of tissue mitochondria.

Activity of mitochondrial enzyme succinate dehydrogenase (SDH) was estimated as a common indicator of energy metabolism [12]. SDH has a central role in mitochondrial metabolism as the only enzyme that is a component of both the TCA cycle and the electron transport chain. SDH catalyzes the oxidation of succinate to fumarate in the mitochondria matrix and transfers electrons to ubiquinone without pumping protons across the mitochondrial inner membrane.

The experiment was carried out on adult outbred male albino rats on a model of carbon tetrachloride-induced liver and brain damage. Intact animals (group $1, \mathrm{n}=10$ ) were not exposed to any manipulations. Groups 2, 3, 4 received $50 \%$ sunflower oil solution of $\mathrm{CCl}_{4}$ subcutaneously: group $2(\mathrm{n}=10)$ and group $3(\mathrm{n}=10)$ - at a single daily dose of $4 \mathrm{ml} / \mathrm{kg}$ for 4 days, group $4(\mathrm{n}=10)$-at a single daily dose of $2 \mathrm{ml} / \mathrm{kg}$ for 7 days. Groups 2 and 4 were studied in 1 day after the last $\mathrm{CCl}_{4}$ administration, group 3-in 7 days after the last $\mathrm{CCl}_{4}$ administration. Carbon tetrachloride introduction causes fat accumulation in liver, hepatic degeneration and hepatitis. Administration of carbon tetrachloride frequently results in marked depression of the central nervous system. The mechanism of $\mathrm{CCl}_{4}$ action is produced in the endoplasmic reticulum by formation of reactive intermediates through isoenzymes of cytochrome P-450. This mechanism also involves significant alterations to mitochondrial calcium homeostasis and is dose-dependent [13].

In groups of intact and carbon tetrachloride-intoxicated rats, we measured the activity of mitochondrial SDH within lymphocytes by cytobiochemical method [12] and pyridine nucleotides reduction parameters (N$\mathrm{ADH}$ fluorescence, speed and duration of reduction) in mitochondria of liver and brain tissues by spectral fluorimetry [14]. We evaluated n-nitrotetrazolium violet reduction by only endogenous substrates (ES) oxidation,

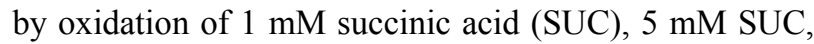
$5 \mathrm{mM}$ SUC in combination with $1.5 \mathrm{mM}$ isocitric acid (ISC) and in a presence of $2 \mathrm{mM}$ malonic acid (MAL).

Pearson correlation coefficients between SDH activity in lymphocytes and speed or duration of pyridine nucleotides reduction in tissue mitochondria, further signed as $r_{\mathrm{SDH} / \mathrm{V}}$ and $\mathrm{r}_{\mathrm{SDH} / \mathrm{T}}$, were used for analyze correlations between the lymphocyte energy status and the functional state of tissue mitochondria.

Microsoft Excel 2010 and Statistica 6.2 were used for statistical analysis. The criterion for significance was $\mathrm{P}<$ 0.05 for all comparisons.

\section{Results}

In our experiments we've demonstrated the existence of correlations between SDH activity in peripheral blood lymphocytes and parameters of pyridine nucleotides reduction in tissue mitochondria.

In group 1 we detected low values of correlation coefficients for lymphocytes and tissue mitochondria by oxidation of ES. Medium values of Pearson correlation coefficients were calculated for lymphocytes and brain tissue mitochondria only by incubating samples with 5 $\mathrm{mM} \mathrm{SUC}+1.5 \mathrm{mM} \mathrm{ISC}\left(\mathrm{r}_{\mathrm{SDH} / \mathrm{T} \text { brain }}=0.72\right)$ and $5 \mathrm{mM}$ $\mathrm{SUC}\left(\mathrm{r}_{\mathrm{SDH} / \mathrm{T} \text { brain }}=-0.66\right)$.

In group 2 we observed high average values of Pearson correlation coefficients by incubating samples with 1 $\mathrm{mM} \mathrm{SUC}\left(\mathrm{r}_{\mathrm{SDH} / \mathrm{T} \text { liver }}=-0.74 ; \mathrm{r}_{\mathrm{SDH} / \mathrm{V} \text { liver }}=0.72\right), 5 \mathrm{mM}$ $\mathrm{SUC}\left(\mathrm{r}_{\mathrm{SDH} / \mathrm{T} \text { brain }}=0.71 ; \mathrm{r}_{\mathrm{SDH} / \mathrm{V} \text { brain }}=-0.76\right)$ and $5 \mathrm{mM}$ $\mathrm{SUC}+1.5 \mathrm{mM}$ ISC $\left(\mathrm{r}_{\mathrm{SDH} / \mathrm{T} \text { brain }}=0.85\right)$.

In group 3 we determined medium values of correlation by oxidation of $\mathrm{ES}\left(\mathrm{r}_{\mathrm{SDH} / \mathrm{V} \text { brain }}=-0.67\right)$ and in a presence of MAL $\left(\mathrm{r}_{\mathrm{SDH} / \mathrm{T} \text { liver }}=-0.68\right)$. High and very high values of coefficients were detected by incubating samples with $1 \mathrm{mM} \mathrm{SUC}\left(\mathrm{r}_{\mathrm{SDH} / \mathrm{T} \text { liver }}=0.83\right), 5 \mathrm{mM} \mathrm{SUC}$ $\left(\mathrm{r}_{\mathrm{SDH} / \mathrm{V} \text { brain }}=0.84 ; \mathrm{r}_{\mathrm{SDH} / \mathrm{T} \text { brain }}=-0.93 ; \mathrm{r}_{\mathrm{SDH} / \mathrm{V} \text { liver }}=-0.87\right)$, $5 \mathrm{mM} \mathrm{SUC}+1.5 \mathrm{mM} \mathrm{IA}\left(\mathrm{r}_{\mathrm{SDH} / \mathrm{T} \text { brain }}=0.84 ; \mathrm{r}_{\mathrm{SDH} / \mathrm{V} \text { brain }}=\right.$ $\left.+0.93 ; \mathrm{r}_{\mathrm{SDH} / \mathrm{T} \text { liver }}=-0.82\right)$ and MAL $\left(\mathrm{r}_{\mathrm{SDH} / \mathrm{T} \text { liver }}=0.88\right)$ as can be seen from Figure 1.

In group 4 high values of $r_{\mathrm{SDH} / \mathrm{v}}$ were detected for lymphocytes and brain tissue mitochondria by incubating samples with $5 \mathrm{mM} \mathrm{SUC}\left(\mathrm{r}_{\mathrm{SDH} / \mathrm{V} \text { liver }}=-0.73\right)$ and $1 \mathrm{mM}$ $\mathrm{SUC}\left(\mathrm{r}_{\mathrm{SDH} / \mathrm{V} \text { liver }}=+0.84\right)$.

We noticed that high and very high correlation between SDH activity and mitochondrial functional state were observed exactly in animal groups with pathology when incubating samples with $1 \mathrm{mM}$ SUC, $5 \mathrm{mM}$ SUC and $5 \mathrm{mM}$ SUC $+1.5 \mathrm{mM}$ ISC.

\section{Preliminary Conclusions}

Basing on the experimental model of carbon tetrachloride-induced liver and brain damage, we've demonstrated 


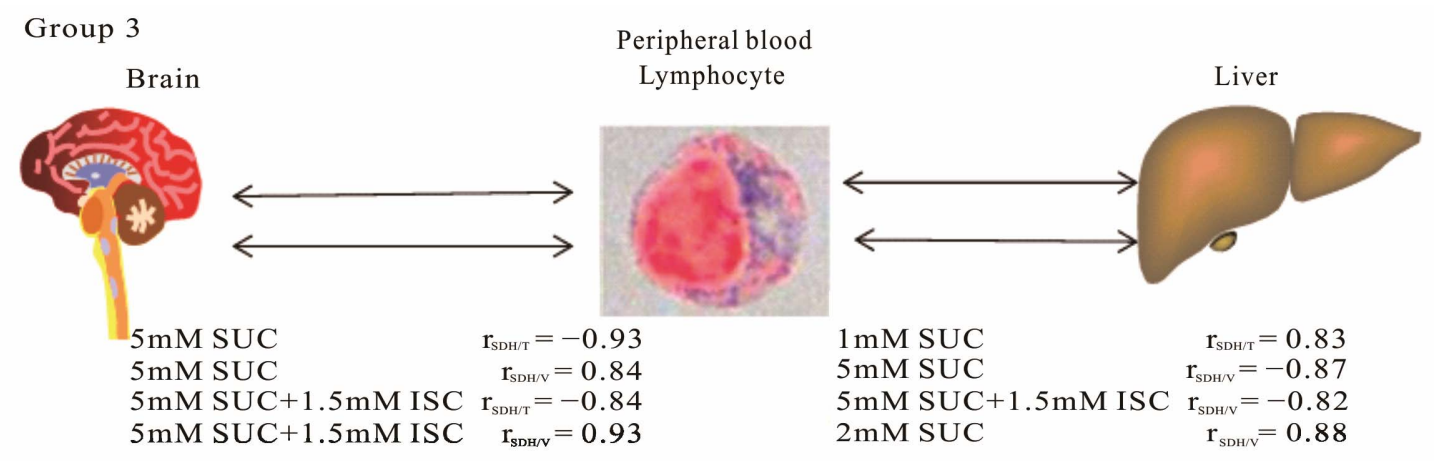

Figure 1. Average values of Pearson correlation coefficients characterizing conjunctions between energy status of peripheral blood lymphocytes and the functional state of tissue mitochondria.

that changes of peripheral blood lymphocyte energy status reflect changes of energy metabolism of the other cells, such as hepatocytes and cells of brain. In pathology we've detected strong and very strong correlations between SDH activity in peripheral blood lymphocytes and pyridine nucleotides reduction parameters in tissue mitochondria under systemic toxic effect of carbon tetrachloride. The existence of correlation between the energy status of peripheral blood lymphocytes and the functional state of tissue mitochondria correspond to the principle of the correlation of parts formulated earlier by Cuvier in the book "Lecons d'Anatomie Comparée": "Every organized individual forms an entire system of its own, all the parts of which naturally correspond...Hence none of these separate parts can change their forms without a corresponding change in the other parts of the same animal".

Cytobiochemical method of SDH activities analysis in peripheral blood lymphocytes is a simple and informative mean to estimate energy metabolism, which allows measuring several parameters of SDH activity at physiological conditions in glass adherent peripheral blood lymphocytes. Demonstrated correlations between the energy status of lymphocytes and the functional state of tissue mitochondria show that cytobiochemical method could be successfully used in daily clinical practice for monitoring of energy metabolism in tissues.

\section{REFERENCES}

[1] N. Bratic and A. Trifunovic, "Mitochondrial Energy Metabolism and Ageing," Biochimica et Biophysica Acta (BBA)-Bioenergetics, Vol. 1797, No 6-7, 2010, pp. 961967. doi:10.1016/j.bbabio.2010.01.004

[2] D. L. Johannsen and E. Ravussin, "The Role of Mitochondria in Health and Disease," Current Opinion in Pharmacology, Vol. 9, No. 6, 2009, pp. 780-786. doi.10.1016/j.coph.2009.09.002

[3] L. D. Osellame, T. S. Blacker and M. R. Duchen, "Cellular and Molecular Mechanisms of Mitochondrial Func- tion," Best Practice \& Research Clinical Endocrinology \& Metabolism, Mitochondria in Endocrinology, Vol. 26, No 6, 2012, pp. 711-723. doi:10.1016/j.beem.2012.05.003

[4] W. S. Lee and R. J. Sokol, "Liver Disease in Mitochondrial Disorders," Seminars in Liver Disease, Vol. 27, No. 3, 2007, pp. 259-273. doi:10.1055/s-2007-985071

[5] C. Frezza and E. Gottlieb, "Mitochondria in Cancer: Not Just Innocent Bystanders," Seminars in Cancer Biology, Vol. 19, No. 1, 2009, pp. 4-11. doi:10.1016/j.semcancer.2008.11.008

[6] M. A. Frohman, "Mitochondria as Integrators of Signal Transduction and Energy Production in Cardiac Physiology and Disease," Journal of Molecular Medicine, Vol. 88, No. 10, 2010, pp. 967-970. doi:10.1007/s00109-010-0662-x

[7] G. M. Enns, "The Contribution of Mitochondria to Common Disorders," Molecular Genetics and Metabolism, Vol. 80, No. 1-2, 2003, pp. 11-26. doi:10.1016/i.ymgme.2003.08.009

[8] J. A. Dykens and Y. Will, "The Significance of Mitochondrial Toxicity Testing in Drug Development," Drug Discovery Today, Vol. 12, No 17-18, 2007, pp. 777-785. doi:10.1016/j.drudis.2007.07.013

[9] F. N. Gellerich, J. A. Mayr, S. Reuter, W. Sperl and S. Zierz, "The Problem of Interlab Variation in Methods for Mitochondrial Disease Diagnosis: Enzymatic Measurement of Respiratory Chain Complexes," Mitochondrion, Vol. 4, No. 5-6, 2004, pp. 427-439. doi:10.1016/j.mito.2004.07.007

[10] A. Mayevsky, R. Walden, E. Pewzner, A. Deutsch, E. Heldenberg, J. Lavee, S. Tager, E. Kachel, E. Raanani, S. Preisman, V. Glauber and E. Segal, "Mitochondrial Function and Tissue Vitality: Bench-to-Bedside Real-Time Optical Monitoring System," Journal of Biomedical Optics, Vol. 16, No. 6, 2011, Article ID: 067004. doi:10.1117/1.3585674

[11] R. P. Narcissov, "Application of P-Nitro-Violet-TetrazoLium for the Quantitative Cytochemistry of Dehydrogenases in Human Lymphocytes," Arkhiv Anatomy, Gistology and Embriology, Vol. 56, 1969, pp. 85-91.

[12] M. N. Kondrashova, M. V. Zakharchenko and N. V. Khunderyakova, "Preservation of the in Vivo State of Mi- 
tochondrial Network for ex Vivo Physiological Study of Mitochondria," International Journal of Biochemistry and Cell Biology, Vol. 41, No. 10, 2009, pp. 2036-2050. doi:10.1016/j.biocel.2009.04.020

[13] M. Jesús Tuñón, M. Alvarez, J. M Culebras and J. González-Gallego, "An Overview of Animal Models for Investigating the Pathogenesis and Therapeutic Strategies in
Acute Hepatic Failure," World Journal of Gastroenterology, Vol. 15, No 25, 2009, pp. 3086-3098. doi:10.3748/wjg. 15.3086

[14] B. Chance, P. Cohen, F. Jobsis and B. Schoener, "Intracellular Oxidation-Reduction States in Vivo," Science, Vol. 137, No. 3529, 1962, pp. 499-508.

doi:10.1126/science.137.3529.499 